\title{
Poderia a Narrativa do Gyges de Platáo Ser uma FicÇÃo Baseada em Heródoto?
}

\author{
Luiz Maurício Bentim da Rocha Menezes ${ }^{I}$
}

\begin{abstract}
RESUMO: Ao contrário daqueles que afirmam que Platão teria se baseado numa antiga fonte para desenvolver sua narrativa sobre Gyges (República, 359d-360b), este trabalho se propóe examinar a hipótese de que esta é, de fato, uma ficção baseada na narrativa de Heródoto (Histórias, I.8-14). Assim, pretende-se investigar o método utilizado por Platão para dar base ao seu argumento filosófico, analisando os pontos da narrativa platônica que divergem da de Heródoto e se esses pontos justificam tomarmos tal narrativa como uma ficção platônica, mais propriamente, um mito criado por Platão com uma função filosófica.
\end{abstract}

PALAVRAS-CHAVE: Platão. Heródoto. Gyges (Giges). Mito platônico.

No Livro II da República de Platão, Gláucon irá contar-nos a história sobre Gyges e seu anel ${ }^{2}$. Tal história faz parte do seu desafio a Sócrates, em que este deve provar que a justiça é de qualquer maneira melhor do que a injustiça para aqueles que a praticam. Em sua narrativa, um grande terremoto abre uma fenda no chão, onde o pastor lídio Gyges cuidava de seu rebanho. Descendo por esta, encontra, entre outras maravilhas [ $\theta \alpha \nu \mu \alpha \sigma \tau \alpha ́$ ], um cavalo de bronze e, dentro deste, um cadáver que possuía unicamente um anel de ouro na mão.

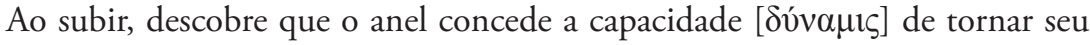
possuidor visível e invisível a sua vontade. Possuindo tal poder, e com a ajuda da Rainha, mata o Soberano da Lídia e assume o poder. Gláucon irá utilizar essa história para ilustrar que os homens só são justos pela força da lei, mas, se puderem agir por sua própria vontade, irão agir com injustiça.

\footnotetext{
1 PPGLM/UFRJ. lmbrmenezes@yahoo.com.br

2 PLATÁO. República, 359b-360b. Utilizamos aqui a tradução de Maria Helena da Rocha Pereira, A República (Lisboa: Fundação Calouste Gulbenkian, 2001). Tomaremos essa tradução como base para nosso artigo, indicando outras traduçôes, inclusive nossas, quando for o caso. Para as passagens da República que pedem o original grego, utilizamos o texto estabelecido por S. R. Slings, Platonis Rempvblicam (Oxford: Oxford University Press, 2003). Demais referências à República serão abreviadas por Rep., indicando-se em seguida a numeração.
} 
Heródoto nos conta a história de Gyges da seguinte maneira ${ }^{3}$ : Candaules, o soberano da Lídia, oferece a Gyges, seu guarda pessoal, a permissão para que este veja sua mulher nua e, assim, possa comprovar que ela é a mais bela. Pois, segundo ressalta Candaules, "[...] os homens confiam menos em seus ouvidos do que em seus olhos" ${ }^{4}$. Mesmo dizendo-se persuadido [ $\left.\pi \varepsilon^{\prime} \theta 0 \mu \alpha 1\right]$ pelas palavras de Candaules de que sua mulher é a mais bela, Gyges é obrigado a ver para comprovar tal fato. Escondido atrás da porta do quarto, Gyges vê a rainha nua e, quando se preparava para se retirar do local, acabou sendo visto por ela sem que ele assim percebesse. Entendendo o ocorrido e percebendo que se tratava de obra de Candaules, a rainha nada fala e aguarda. No dia seguinte, a rainha chama Gyges em sua presença e apresenta a este

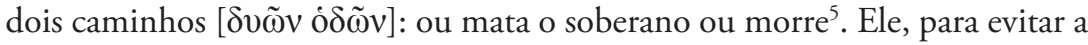
morte, escolhe matar o soberano e assim toma para si a mulher e a soberania

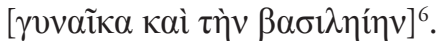

Apesar de existirem outras versôes da chegada de Gyges ao poder, estas duas são as mais conhecidas e antigas versóes. Mesmo possuindo diferenças, que abordaremos ao longo deste artigo, elas apresentam semelhanças, como a questão da visibilidade, da peculiaridade da usurpação do poder e da união com a rainha. Esses fatores poderiam aparecer em qualquer história de usurpação e, portanto, o que realmente aproxima as narrativas é que ambas possuem os termos "Lídia" e "Gyges", fazendo com que seus temas entrem em conexão.

Kirby Flower Smith acredita que tanto Platão como Heródoto tiveram antes uma fonte comum da qual eles desenvolveram suas narrativas. Em seu trabalho, Smith tenta reconstruir aquela que seria a mais antiga lenda sobre Gyges?. No entanto, o próprio Smith admite, em nota, que "[...] a lenda clássica de um anel da invisibilidade vem à tona somente em conexão com

\footnotetext{
${ }^{3}$ HERÓDOTO. Histórias, I.8-15. Utilizamos a tradução de José Ribeiro Ferreira e Maria de Fátima Silva Histórias - Livro I (Lisboa: Ediçôes 70, 2002). Tomaremos esta tradução como base para nosso artigo, indicando outras traduçôes, inclusive nossas, quando for o caso. Para as passagens das Histórias que pedem o original grego, utilizamos o texto estabelecido por Carolus Hude, Herodoti Historiae, Tomus I, (Oxford: Oford University Press, 1927). Demais referências às Histórias serão abreviadas por Hdt., indicando-se em seguida a numeraçấo.

${ }^{4}$ Hdt. I.8.2.

${ }^{5}$ Hdt. I,11.2-3.

${ }^{6}$ Hdt. I,12.2.

7 SMITH, K. F. The Tale of Gyges and the King of Lydia. AJPh, v. 23, n. 3 (p. 261-282) e n. 4 (361387), 1902.
} 
Gyges e, pela primeira vez, na passagem de Platão em discussão"8. Segundo

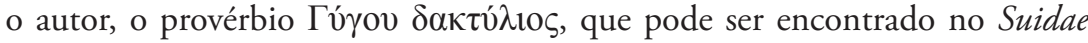

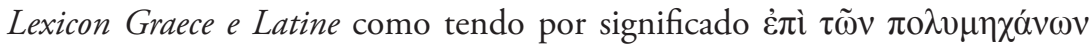

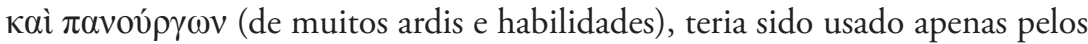
autores mais tardios, não havendo nenhum provérbio antes de Platão. Assim sendo, tentaremos neste trabalho seguir a hipótese de Andrew Laird' de que Platão teria inventado sua versão da história, inspirado primariamente pela leitura da versão de Heródoto, analisando os pontos da narrativa platônica que divergem da de Heródoto e se esses pontos justificam tomarmos tal narrativa como uma ficção platônica, mais propriamente, um mito criado por Platão com uma função filosófica.

Ao começarmos nossa análise, já podemos notar uma diferença entre as narrativas apresentadas: Heródoto menciona Gyges; Gláucon, no princípio de sua história, na passagem $359 \mathrm{~d}$, alude a uma capacidade concedida ao " [...]

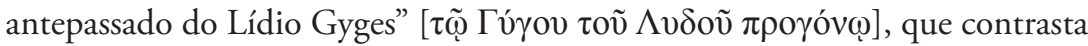

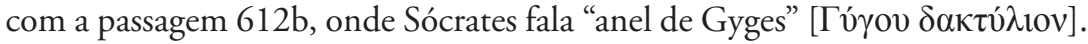
O problema da passagem 359d é muito estudado pelos comentadores e estudiosos da República, e uma vasta bibliografia sobre a questão foi produzida. Mesmo sem entrarem num acordo, os estudiosos tentam de alguma maneira harmonizar as passagens, fazendo com que, na verdade, o possuidor do anel seja Gyges. Não nos propomos resolver o problema aqui, já que isso seria por demais extenso, mas nos limitaremos a um breve resumo de nossas conclusóes $^{10}$. Se Gyges é o Lídio citado e o antepassado é aquele que encontrou o anel e tomou o poder, entáo, por que Gyges teria a mesma necessidade de derrubar o soberano da Lídia? Heródoto o apresenta como sendo homem da guarda pessoal de Candaules, soberano da Lídia (Hdt. I.8.1), e não há nada que cite um reinado de tal antepassado ou uma possível derrubada deste ou de um de seus descendentes. A inconsistência entre as histórias de Gláucon e Heródoto pode significar uma das seguintes alternativas: (i) eles não utilizam a mesma fonte para contar suas histórias; (ii) a narrativa de Heródoto tem uma influência limitada sobre a narrativa de Platão; (iii) Heródoto é o modelo central para Platão e há um significado para essa inconsistência.

\footnotetext{
${ }^{8}$ SMITH, K. F. The Tale of Gyges and the King of Lydia. AJPh, v. 23, n. 3, nota 2, p. 268.

9 LAIRD, A. Ringing the Changes on Gyges: Philosophy and the Formation of Fiction in Plato's Republic. JHS, v. 121, 2001, p. 12-29.

10 O problema da passagem 359d está mais bem analisado em MENEZES, L. M. B. R. Nova Interpretaçăo da passagem 359d da República de Platăo. Kriterion, v. 53, n. 125, p. 29-39, 2012.
} 
Mesmo havendo uma remota possibilidade de (i) ser verdadeira, não obtemos provas que possam comprovar sua veracidade. A opção (ii) levaria novamente à suposição de uma segunda fonte de influência para Platão ou que a leitura de Heródoto o levou a desenvolver uma narrativa diferente com outro objetivo, o que, de fato, é a opção (iii). É nesta opção que Laird faz sua aposta, pois, segundo ele, " [...] a suposição de que deve haver um original para inspirar a história do anel de Platão nunca acomodou a possibilidade de Platáo construir, talvez bastante diretamente, de Heródoto" ${ }^{11}$, não necessitando ter uma fonte à parte.

Para Laird, o fato de Gláucon se referir a um ancestral do Lídio Gyges já é um indício de que Platão está a construir uma ficção que não precisa necessariamente seguir a linhagem dada por Heródoto. Assim como é Sócrates, e não Gláucon, que fala num anel de Gyges, visto que estaria mais preocupado com a situaçáo contrafactual que o anel proporciona do que aquele que, de fato, o usa. Concordamos que Platão parece não estar preocupado com a genealogia lídia, ao compor o seu mito, mas apenas interessado no argumento filosófico a ser desenvolvido. No entanto, tomaremos, para harmonia das passagens citadas da República e concordância com Heródoto, como sendo Gyges ele mesmo o autor das proezas contadas por Gláucon.

Seguindo o caminho de Laird, Gabriel Danzig irá investigar em seu trabalho $^{12}$ quais seriam os motivos de Platão para incluir certos elementos em sua história que não aparecem em Heródoto; e o que há na história de Heródoto que possa ser útil para Platão, tentando com isso provar que a história de Gyges é uma fábula politicamente vantajosa. Para ele, a história de Gyges é mais do que uma hipótese irreal, mas um desafio sofístico onde a invisibilidade representaria o poder da retórica. Tomaremos a análise desses elementos feita por Danzig para situarmos as diferenças existentes entre as narrativas.

O primeiro elemento por ele levantado é que Platão teria colocado Gyges como sendo um simples pastor, para enfatizar a injustiça de Gyges, que sai de pastor para governante ${ }^{13}$. O segundo elemento é o anel ter sido encontrado nos subterrâneos de uma caverna aberta por um terremoto. De

\footnotetext{
${ }^{11}$ LAIRD, op. cit., p. 14.

12 DANZIG, G. Rhetoric and the Ring: Herodotus and Plato on the Story of Gyges as a Politically Expedient Tale. G\&R, v. 55, n. 2, 2008, p. 169-192.

${ }^{13}$ Ibid., p. 188.
} 
acordo com Danzig, o subterrâneo poderia estar ligado tanto à nobre mentira (Rep., 414b et seq.) quanto à analogia da caverna (Rep., 514a et seq.). $\mathrm{Na}$ nobre mentira, os cidadãos nasceram da terra, de modo que a terra é a mãe desses cidadáos e deve ser por eles defendida. Na analogia da caverna, os cidadãos são representados como vivendo no subterrâneo de uma caverna não muito diferente da a que Gyges desceu. A caverna é um lugar no qual homens acorrentados veem sombras projetadas na parede de objetos que outros homens colocam em frente à luz do fogo. Aqui, segundo Danzig, a caverna é a representação da cidade, que exerce uma poderosa influência sobre o caráter e opinião dos homens. Essa imagem pode servir como uma explicação do significado por trás da nobre mentira: os cidadãos são nascidos da terra e a terra é mãe deles, uma vez que percebemos que a terra representa a comunidade política $^{14}$. Para Danzig, a exibição das imagens na caverna significa, entre outras coisas, o poder dos retóricos e poetas para controlar o dêmos. A descida de Gyges à caverna e a tomada do anel mágico indica que Gyges ganhou um poder retórico que lhe permite escravizar as pessoas de sua comunidade política. A relação é feita entre os termos $\theta \alpha v \mu \alpha \sigma \tau \alpha$, que indica as maravilhas vistas por Gyges no subterrâneo (359d6), $\theta \alpha v \mu \alpha \tau o \pi$ oıó, que é utilizado para nomear os construtores das imagens exibidas na caverna (514b6) e $\theta \alpha v ́ \mu \alpha \tau \alpha$, que se refere às imagens projetadas na caverna (514b7). Para ele, a relação entre esses termos é análoga: o anel de Gyges dá-lhe a mesma capacidade retórica que aprisiona homens em cavernas ${ }^{15}$. O terceiro elemento, enumerado por Danzig, é o cadáver encontrado no subterrâneo da caverna que somente possuía o anel em seu dedo. Para ele, Platão transformou analogicamente a beleza da rainha nua no cadáver nu de sua história, associando a nudez como símbolo da realidade natural que se encontra abaixo das convençôes da cultura humana. Por último, o cadáver se encontra dentro de um cavalo de bronze. $\mathrm{O}$ autor se baseia em Hanfmann para dizer que a arqueologia não encontrou um caso de um homem enterrado dentro de uma réplica de cavalo ou outro animal, embora haja vários casos de pessoas enterradas com seus cavalos ${ }^{16}$. Por isso, Danzig sugere que a imagem do cadáver com um cavalo de bronze pode ser uma variante da imagem do homem com várias cabeças de animais da passagem 588b-589b e, como um resultado da procura de objetos que tenham um poder retórico, a parte animal superou a humana e agora a parte humana está morta.

\footnotetext{
${ }^{14}$ DANZIG, G., p. 188-9.

15 Ibid., p. 189.

${ }^{16}$ HANFMANN, G. M. A. Lydiaka. HSPh., v. 63, 1948, p. 76-79.
} 
Para responder a Danzig, começaremos pelo cavalo de bronze. Não nos parece que ele tenha lido corretamente Hanfmann, pois este assim escreve: " [...] o cavalo de bronze, presumivelmente, uma construção humana, é intrigante. Uma explicação possível pode estar na existência de um ritual de um deus, no qual um cavalo artificial tinha uma parte. Tal ritual existia na Anatólia; e o cavalo de bronze tinha um papel nisto" ${ }^{17}$. Apesar de não poder especificar onde, Hanfmann acredita que o cavalo de bronze é uma influência oriental à narrativa platônica. Além do mais, parece-nos por demais inconsistente a hipótese de Danzig de relacionar a imagem do homem com várias cabeças não humanas com o cadáver da história de Gyges. Primeiro, porque não há nessa imagem monstruosa nada que remeta a um cavalo de bronze e, a despeito de uma cabeça de cavalo poder ser pressuposta compondo uma das muitas cabeças da imagem, não nos parece que estejamos fazendo a analogia corretamente, ao associarmo-na ao homem morto dentro de um cavalo de bronze, já que tal homem é um gigante, não é tripartido e não possui qualquer indício que nos leve a compô-lo com muitas cabeças de animais. Da mesma maneira, a morte do homem, pelas demais cabeças na passagem indicada, é causada pela injustiça e não pelo poder da retórica, e tomá-las como sinônimos náo nos parece adequado.

A relação dos subterrâneos na história de Gyges com a analogia da caverna e a nobre mentira, ainda que interessante, não nos parece consistente da maneira como Danzig colocou. A comparação com a analogia da caverna foi um tanto breve para a dificuldade existente na mesma. A relação entre $\theta \alpha v \mu \alpha \sigma \tau \alpha \dot{\alpha}, \theta \alpha v \mu \alpha \tau o \pi$ oloí e $\theta \alpha v ́ \mu \alpha \tau \alpha$ é pertinente e bem feita, mas se torna vaga, sem investigar o resto da caverna. A princípio, não consideramos viável uma relação entre a "caverna" e o "Gyges", porém, se Danzig estiver correto em sua análise, algumas questôes que deveriam ser respondidas ficaram pendentes em seu trabalho. A principal, a nosso ver, seria o que significa a descida de Gyges à caverna? Não vemos qualquer meio cabível para considerálo o filósofo que vai libertar os demais cidadãos acorrentados. Dessa forma, se Gyges não é o filósofo em questão, por que no início da narrativa ele estaria na superfície?

Uma passagem intrigante da analogia da caverna nos faz talvez tomar um rumo náo tấo direto com esta. Ao tratar do regresso do prisioneiro à caverna, Platão irá citar Homero para caracterizar o prisioneiro fugido, de que seria seu intenso desejo " $[\ldots]$ servir junto de um homem pobre, como

${ }^{17}$ HANFMANN, G. M. A., p. 76. A tradução é nossa. 
servo da gleba"18 e antes sofrer tudo mais, do que regressar àquelas ilusóes e viver daquele modo ${ }^{19}$, o que é uma clara referência à fala a Aquiles, quando Odisseu o felicita por continuar a ser rei no Hades. O início do mito de Gyges faz uma clara analogia com os mitos sobre o Hades, pois, mesmo não tratando

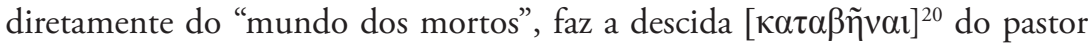
por uma fenda $[\chi \alpha ́ \sigma \mu \alpha]$ na qual este viu muitas maravilhas $[\theta \alpha v \mu \alpha \sigma \tau \alpha \dot{ }]$. Ou seja, Gyges faz o rito de passagem necessário para se chegar ao outro lado e daí

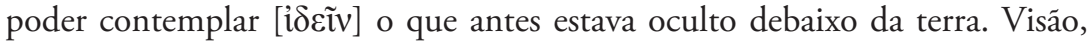
admiração e descida estão presentes em seu princípio. A narrativa apresenta uma forte analogia com o visível, e irá indicar o seu tema a cada instante em que é contada. Gyges se admira porque vê e essa é a chave para o movimento de descida realizado no mito rumo ao conhecimento das maravilhas que ocultas estão. Schuhl nos chama atenção para o cavalo como um símbolo de morte ${ }^{21}$, assim como também salienta que, sendo um "[...] animal ctônico, o cavalo é estreitamente ligado a Poseidon, deus "I $\pi \pi \imath \mathrm{s}$, e mesmo "I $\pi \pi \mathrm{o}$, a Hades $\kappa \lambda \nu \tau$ ó $\pi \omega \lambda$ os; manifesta-se em um poder demoníaco, fúnebre e inquietante"22. Mackay irá reforçar, afirmando que um terremoto é muitas vezes simbolizado com a figura do cavalo e que isso está ligado a Poseidon ${ }^{23}$. Lembremos que a narrativa começa com um terremoto, o que dá indícios da ação do deus sobre o acontecimento. Apesar disso, conforme Mackay, a relação do cavalo não é limitada a Poseidon, porque também pode ser símbolo direto dos poderes do subterrâneo ${ }^{24}$, relacionado a Hades, o que reforçaria a nossa tese que liga a narrativa de Gyges aos mitos sobre o Hades.

Quanto à nobre mentira, Danzig a emprega com relação à narrativa de Gyges sem examinar devidamente o mito. Conta o mito de que os homens são nascidos da terra e, dependendo da função de cada um, há um tipo de metal diferente em sua composição. Os governantes têm ouro em sua composição, os auxiliares, prata, e os artífices, ferro e bronze. Dois desses metais aparecem

\footnotetext{
${ }^{18}$ Odisséia, XI. 489-490.

${ }^{19}$ Rep., $516 \mathrm{~d}$.

20 Podemos comparar a descida de Gyges àquela que Odisseu vivo fez ao Hades, no Canto XI da Odisséia.

${ }^{21}$ SCHUHL, P. M. Études sur la Fabulation Platonicienne. Paris: Presses Universitaires de France, 1947 , p. 80. Tradução nossa.

${ }^{22}$ HESÍODO. Os Trabalhos e os Dias, 148. Tradução de M. C. N Lafer. São Paulo: Iluminuras, 1996. Demais citaçôes dessa obra serão abreviadas por Trabalhos, indicando-se a seguir os versos.

23 Trabalhos, 152-155.

${ }^{24}$ Rep., 415c.
} 
na narrativa sobre Gyges: o anel é de ouro e o cavalo é de bronze, mas Danzig ignora completamente esse fato. Todavia, se levarmos isso em consideração, que relação poderíamos estabelecer entre os mitos? Ao que tudo indica, a relação entre estes é estranha se assim colocarmos, porque o mito dos metais, ligado à nobre mentira, é contado posteriormente e pela boca de Sócrates, enquanto Gyges é dito por Gláucon. No entanto, se pensarmos que o mito dos metais é anteriormente contado por Hesíodo, que se baseia em fontes orientais, poderemos estabelecer uma relação entre estes. Os da raça de bronze, que é a terceira na ordem contada por Hesíodo, com o bronze trabalhavam, sendo terríveis e fortes seguidores de Ares. Teriam grande força e braços

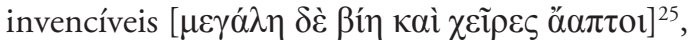

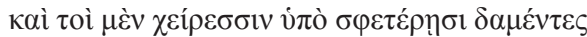

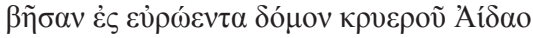

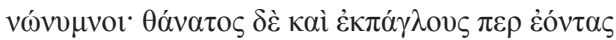

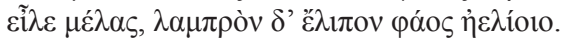

e por suas próprias mãos tendo sucumbido,

desceram ao úmido palácio do gélido Hades;

anônimos; e a morte, por assombrosos que fossem,

pegou-os negra. Deixaram, do sol, a luz brilhante. ${ }^{26}$

Foram assim ocultados pela terra, deixando a superfície. Esta é a primeira raça em que Hesíodo faz uma referência textual direta à morte e à descida para o Hades, lembrando-nos de que eles assim fizeram por suas próprias mãos, o que pode significar que eles se mataram uns aos outros. Ao pensarmos numa relação com Platão, recordemos que o cadáver, que se encontra num cavalo de bronze, não possui nome, sendo anônimo como a

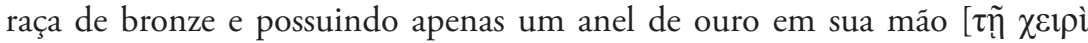
$\chi \rho v \sigma o \tilde{v} \delta \alpha \kappa \tau u ́ \lambda$ iov], o que pode ser um indício da possível causa de sua morte, sina da raça de bronze de morrer por sua própria mão. Esse cadáver, assim como os homens de bronze de Hesíodo, deixou de ser visível, pois longe da luz do sol está. A palavra grega para luz, póos, usada por Hesíodo, tem a mesma etimologia daquela utilizada na história de Gyges para se referir ao visível, pavepós. Se os homens de bronze deixaram a luz, foram ocultos pela

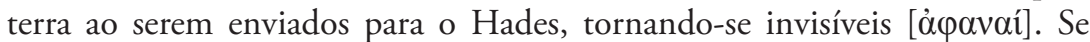
pensarmos que Gyges é pastor e, portanto, pertence à classe dos artífices, teria, de acordo com a nobre mentira, o bronze em sua composição, como o cavalo

25 Rep., 329e.

${ }^{26}$ DANZIG, op. cit., p. 187 et seq. 
da história. Admirado com o anel de ouro, Gyges se apossa deste. Ao depor o soberano da Lídia, que por ser governante possui ouro em sua composição, Gyges se torna um falso governante, pois é um governante de bronze, que apenas parece ser de ouro. Isso decreta o fim do bom governo e da cidade, já que é dito no mito da nobre mentira que "[...] a cidade seria destruída quando um guardiāo de ferro ou de bronze a defendesse" 27 .

$\mathrm{O}$ anel tem um papel importante na analogia com os mitos sobre o

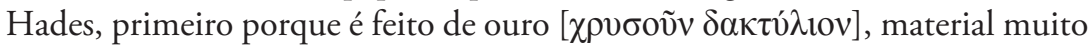
cobiçado pelos muitos $(p o l l o i)^{28}$ e que provavelmente influenciou a sua escolha entre as demais maravilhas escondidas e, depois, apesar da história de Gyges não ter qualquer tipo de luz capaz de se opor às sombras da caverna, o que torna a relação do "Gyges" com a analogia da caverna ainda menor, é interessante notarmos que o anel é um artefato com uma dupla dýnamis, capaz de tornar

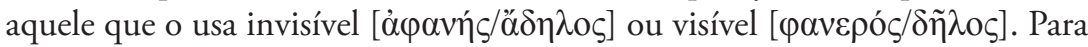
os gregos, Hades é um nome duplo que indica tanto o senhor do invisível, que reina abaixo da terra, como esse lugar subterrâneo, desconhecido e escondido para aqueles que estáo sobre a terra. Se entendermos isso, podemos perceber que aquele que se utilizar do anel para se tornar invisível terá o mesmo poder de Hades, tornando-se oculto para os demais. Lembremos que na Rep. X, 612b3-

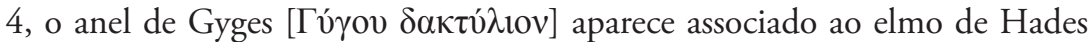

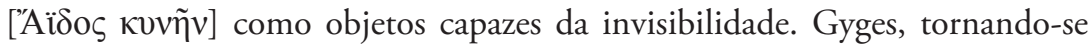
senhor desse poder, será capaz de oscilar entre os dois mundos: o visível e o invisível. $\mathrm{O}$ anel de Gyges demonstra que as pessoas praticam a justiça como algo necessário, mas não como algo bom por si mesmo, uma vez que, no íntimo de cada homem, existe o desejo de cometer injustiça como bem agradável. $\mathrm{O}$ verdadeiro governante não precisa usar o anel para se tornar invisível, mas somente visível deve ser como um rei. Se levarmos em conta a analogia com a nobre mentira, e considerarmos que o ouro compóe o verdadeiro governante, o anel de ouro torna-se um artefato necessário ao governo, porém, o tipo de governo é determinado por quem usa o anel e de que maneira o usa. Sendo visível, é um verdadeiro governante; invisível, um falso governante.

A tese de Danzig de que o anel é a representação do poder retórico ${ }^{29}$ se baseia na afirmação de Gláucon de que "[...] o supra-sumo da injustiça é

\footnotetext{
${ }^{27}$ Rep., 361a.

${ }^{28}$ Rep., $361 \mathrm{~b}$.

${ }^{29}$ Rep., 360e6-361a1.
} 
parecer justo sem o ser" ${ }^{30}$ e que, para o homem que deseje tornar isso possível, deve "ser suficientemente hábil a falar, para persuadir" ${ }^{1}$. No entanto, este é apenas um dos fatores necessários enumerados por Gláucon. $\mathrm{O}$ anel representa mais do que o mero uso do poder retórico, pois um homem só poderia agir pela injustiça se pudesse ocultar aos demais seus atos injustos. Para que isso seja possível, é preciso que o injusto faça como os artífices qualificados

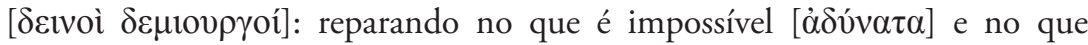

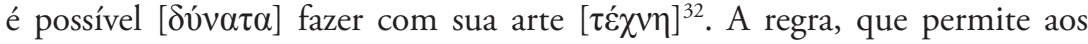
deinoì demiourgoí agirem no limite da sua dýnamis, é a mesma que possibilita ao injusto determinar o que é possível a ele e como deve fazer se quiser ser

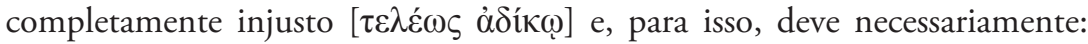

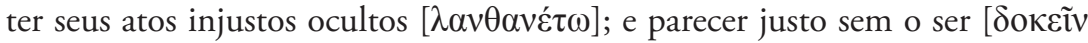

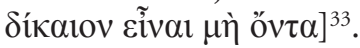

$\mathrm{O}$ anel de Gyges com sua dýnamis permite que tais premissas sejam cumpridas: simboliza tal capacidade necessária que faculta àquele que assim agir náo seja punido por seus atos injustos. Mas, para que possa desenvolver tal capacidade, o injusto deve ter as seguintes habilidades: persuasão [ $\pi \varepsilon i ́ \theta \varepsilon \imath v]$, para reparar algum erro; e violência [ $\beta i ́ \alpha \zeta \omega]$, caso alguma de suas injustiças seja denunciada ${ }^{34}$.

Ser completamente injusto é ser tirano e, para que isto possa se realizar, o injusto deve agir no limite de sua dýnamis, sabendo separar o que ele pode do que não pode fazer. A dýnamis do anel é o que permite Gyges agir como um tirano, porque o torna capaz de ocultar seus atos injustos dos demais. Se um homem pudesse separar adequadamente o que pode do que náo pode fazer e soubesse o que deve ocultar em suas açóes dentro das habilidades que competem ao verdadeiro injusto, esse homem poderia atingir a tirania como a forma de governo que compete a tal homem e teria uma vida feliz, segundo o vulgo. $\mathrm{O}$ fato de poder estar visível e invisível quando quiser faz da tirania o governo do injusto, o qual comete suas injustiças ocultamente, para obter aquilo que seu desejo indica como um bem, e parece justo quando visível está, enganando todos os demais que por ele são governados de que seu governo é bom e justo. Tal fato faz de Gyges o tirano por excelência.

\footnotetext{
${ }^{30}$ Rep., 361a2-5.

${ }^{31}$ Rep., $361 \mathrm{~b}$.

${ }^{32}$ Rep., 360e6-361a1

${ }^{33}$ Rep., 361b2-4.

${ }^{34}$ Rep., 361b2-4.
} 
A história de Gyges contada por Gláucon é assumidamente uma história contada pelos muitos (polloî). Essa estratégia de Platão coloca a narrativa como uma mitologia popular que corre na boca dos polloi. Se tomarmos o mito conforme Platão o coloca no Livro II como sendo formador e educador desde a paideía infantil, podemos talvez tomar Gyges como um mito de base, que sustenta em sua concepção a educação desse tipo de pensamento dos polloí. A reproduçáo dos polloi do mito contado por Gláucon faz-nos entender que existe muito mais do que o fato de narrar um acontecimento fantástico, mas uma crença numa determinada concepção de justiça e numa certa conduta da natureza humana, que vem sendo ensinada desde a juventude. Se entendermos que a tirania é um tipo de governo no qual se usurpa o poder e se governa para alimentar seus próprios desejos, podemos compreender que o mito de Gyges contado por Gláucon é um mito fundador da tirania. Ou seja, o mito de Gyges é um mito do desejo dos polloi de se tornarem tiranos, o que acarretará na resposta de Sócrates a esse mito através de outro, o mito dos metais. Se algum dos polloí, que pertencem à classe dos artífices e, portanto, tendo bronze a sua composiçáa, assumir o poder da cidade como governante, faria de seu governo uma tirania, o que acarretaria no fim do bom governo e da cidade justa.

Ao criarmos um paralelo com Heródoto, veremos que sua história é um típico caso de usurpação do poder. Contudo, seu Gyges, ao contrário do de Platão, é retratado como sendo inocente ${ }^{35}$ em seus atos, pois tanto a visão da rainha nua como o assassinato do rei foram-lhe impostos. $\mathrm{O}$ que a princípio é uma diferença entre as narrativas pode, se for mais bem analisado, ser tomado como um caso onde a aparência se sobressai a essência. Gyges, em Heródoto, pode parecer ser inocente, mas não o é de fato. Com o uso da retórica, persuade os demais de que é inocente na história e se utiliza da violência para tomar o trono e se instalar no poder como um tirano.

Seguindo essa interpretação, podemos claramente associar as narrativas como também manter a consistência da hipótese de que Platão teria se baseado em Heródoto, apesar das diferenças, para compor seu mito da tirania do anel..$^{36}$

35 Cf. DANZIG, op. cit., p. 172-174.

${ }^{36}$ Gostaria de agradecer pelo apoio, leitura e contribuição a Carolina Araújo e Maria Elizabeth Godoy. 
MENEZES, Luiz Maurício B. R. Could Plato's Gyges narrative be a fiction based on Herodotus? Trans/Form/Açâo, Marília, v. 36, n. 3, p. 9-22, Set./Dez., 2013.

\begin{abstract}
Opposite to those who inferred that Plato might have developed his Gyges narrative based on an ancient source (Republic, 359d-360b), this paper aims to examine the hypothesis that this is in fact a fiction based on Herodotus' narrative (Histories, I.8-14). Therefore, it intends to investigate the method used by Plato to base his philosophic argument, analyzing the points in the platonic narrative which differ from Herodotus', and whether these points enhance our perception of its fictitious nature, or better, a myth created by Plato with a philosophic purpose.
\end{abstract}

KEYWORDS: Plato, Herodotus, Gyges, platonic myth.

\title{
REFERÊNCIAS
}

\section{Ediçóes e Traduçóes da República de Platáo}

PEREIRA, M. H. R. A República. Traduçáo de Maria Helena da Rocha Pereira. 9 ed. Lisboa: Fundação Calouste Gulbenkian, 2001.

SLINGS, S. R. Platonis Rempvblicam, recognovit brevique adnotatione critica instrvxit: S. R. Slings. Oxford: Oxford University Press, 2003.

\section{Ediçốes e Traduçóes de Heródoto}

FERREIRA, J. R.; SILVA, M. F. Livro 1. Tradução e Notas de José Ribeiro Ferreira e Maria de Fátima Silva. Lisboa: Edições 70, 2002.

HUDE, C. Herodoti Historiae, Tomvs I. recognovit brevique adnotatione critica instrvxit: Carolvs Hude. Oxford: Oxford University Press, 1927.

\section{Ediçóes e Traduçốes de Clássicos Gregos}

HESÍODO. Os Trabalhos e os Dias. Tradução de M. C. N. Lafer. São Paulo: Iluminuras, 1996.

HOMERO. Odisséia. Tradução e notas de Trajano Vieira. São Paulo: Editora 34, 2011. 


\section{Estudos}

DANZIG, G. Rhetoric and the Ring: Herodotus and Plato on the Story of Gyges as a Politically Expedient Tale. Greece \& Rome, v. 55, n. 2, p. 169-192, 2008.

FRUTIGER, P. Les Mythes de Platon. Reprint of 1930 ed. New York: Arno Press, 1976.

HANFMANN, G. M. A. Lydiaka. Harvard Studies in Classical Philology, v. 63, p. 65-88, 1948.

LAIRD, A. Ringing the Changes on Gyges: Philosophy and the Formation of Fiction in Plato's Republic. Journal of Hellenic Studies, v. 121, p. 12-29, 2001. MACKAY, L. A. The Earthquake-Horse. Classical Philology, v. 41, n. 3, p. 150-154, 1946.

MENEZES, L. M. B. R. Nova Interpretação da Passagem 359d da 'República' de Platão. Kriterion, v. 53, 125, p. 29-39, 2012.

SCHUHL, P. M. Études sur la Fabulation Platonicienne. Paris: Presses Universitaires de France, 1947.

SMITH, K. F. The Tale of Gyges and the King of Lydia. The American Journal of Philology, v. 23, n. 3, p. 261-282, 1902. . The Tale of Gyges and the King of Lydia. AJPh, v. 23, n. 4, p. $361-$ $387,1902$.

Recebido em: 27.11.2012

Aceito em: 15.06.2013 
MENEZES, L. M. B. R.. 